\title{
Combined study of time-series bifurcation and power spectral behaviour of a thalamo-cortico- thalamic neural mass model
}

\author{
Basabdatta Sen-Bhattacharya
}

From Twenty Second Annual Computational Neuroscience Meeting: CNS*2013

Paris, France. 13-18 July 2013

A combined power spectral and time-series bifurcation analysis of a neural mass model is presented. Such 'multimodal' analytical techniques are being used in several researches to understand Electroencephalograph (EEG) anomalies in brain disorders [1][2], in contrast to 'power spectra-only' analytical studies that were more common during the early days of EEG analysis. In a recent work, a combined analysis of a simple thalamo-cortical neural mass model in context to EEG abnormality in Alzheimer's disease (AD) is presented [3]. The study shows that 'unimodal' analytical techniques such as power spectra-only studies without a simultaneous observation of the timeseries model output may lead to anomalous conclusions and hypotheses. Towards this, in this work, a 'multimodal' analytical technique is applied on a thalamocorticothalamic (tct) model, which was earlier studied using

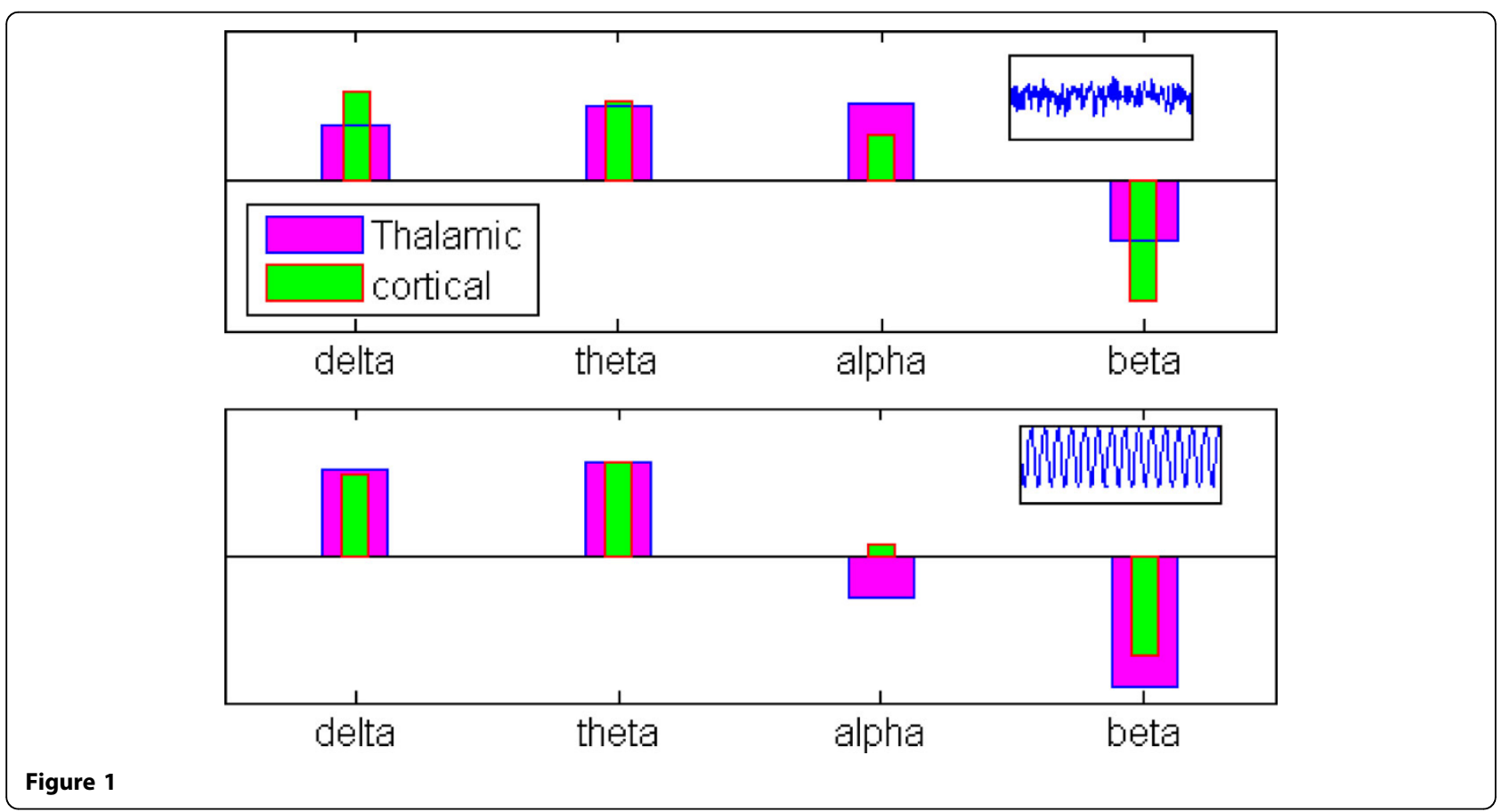

Correspondence: bbhattacharya@lincoln.ac.uk

School of Engineering, University of Lincoln, Lincoln, LN6 7TS, UK

(c) 2013 Sen-Bhattacharya; licensee BioMed Central Ltd. This is an Open Access article distributed under the terms of the Creative 
power-spectra analysis only [4]. The tct model is an enhanced version of that used in [3] and is based on biological data available in current literature. Furthermore, it aims to mimic thalalmocortical oscillations such as observed in the EEG of both healthy and diseased brain.

Here, the power spectra of the tct model output is observed within the $\delta(1-3 \mathrm{~Hz}), \theta(4-7 \mathrm{~Hz}), \alpha(8-13 \mathrm{~Hz}), \beta$ $(14-30 \mathrm{~Hz})$ bands, along with a simultaneous analysis of the time series behaviour, the latter showing three behavioural modes: noisy point-attractor, spindle and limitcycle. With all parameters at their basal values, the output time series is in a noisy point-attractor mode with maximum power within the alpha band (Figure 1). However the model shifts into a limit cycle oscillatory mode with a decrease in inhibitory connectivity parameters in the model (Figure 1); the corresponding power spectra show an increase in peak power within the $\theta$ and $\delta$ bands along with a simultaneous decrease in power within the $\alpha$ and $\beta$ bands. The model behaviour is very much in agreement with in-vitro studies [5] which report an increased theta band power and a simultaneous decreased alpha band power during transition from wakefulness to sleep. Furthermore, the in-vitro time-series are qualitatively very similar to those obtained using the model. Thus, the model indicates a decreased inhibitory activity to be the neural correlate of the transitive state between wakefulness and sleep. On the other hand, increased mean firing activity of the extrinsic model inputs pushes the model, first into a spindling mode, and then into a limit cycle mode. In this state, the power within the delta band shows a significant increase compared to those within the other frequency bands. This behaviour is more similar to in-vivo studies of awake-to-sleep transition as reported in [5].

Published: 8 July 2013

\section{References}

1. Stam CJ: Nonlinear dynamical analysis of EEG and MEG: review of an emerging field. Clin Neurophysiol 2005, 116:2266-2301.

2. Marten F, Rodrigues S, Suffczynski P, Richardson MP, Terry JR: Derivation and analysis of an ordinary differential equation mean-field model for studying clinically recorded epilepsy dynamics. Phys Rev E 2009, 79:1-7.

3. Sen-Bhattacharya B, Cakir Y, Serap-Sengor N, Coyle D, Maguire LP: Modelbased bifurcation and power spectral analyses of thalamocortical alpha rhythm slowing in Alzheimer's Disease. Neurocomp 2013, doi 10.1016/j. neucom.2012.10.023.

4. Sen-Bhattacharya B, Coyle D, Maguire LP: A thalamo-cortico-thalamic neural mass model to study alpha rhythms in Alzheimer's Disease. Neur Netw 2011, 24:631-645.

5. Hughes SW, et al: Synchronised oscillations at $a$ and $\theta$ frequencies in the lateral geniculate nucleus. Neuron 2004, 42:253-268.

doi:10.1186/1471-2202-14-S1-P18

Cite this article as: Sen-Bhattacharya: Combined study of time-series bifurcation and power spectral behaviour of a thalamo-cortico-thalamic neural mass model. BMC Neuroscience 2013 14(Suppl 1):P18.

\section{Submit your next manuscript to BioMed Central and take full advantage of:}

- Convenient online submission

- Thorough peer review

- No space constraints or color figure charges

- Immediate publication on acceptance

- Inclusion in PubMed, CAS, Scopus and Google Scholar

- Research which is freely available for redistribution

Submit your manuscript at www.biomedcentral.com/submit 